\title{
Patternmaking of slim-fit jacket sloper for men in their 30's according to numbers of jacket buttons Part 1 \\ - Focusing on ease -
}

\author{
Myoung-Ok Kim and Kyung-A Kim ${ }^{* \dagger}$ \\ Dept. of Fashion Design, Howon University, Gunsan, Korea \\ Dept. of Fashion Textile Ceramic, Myongii College, Seoul, Korea*

\section{0 대 남성복 슬림 핏 재킷의 버튼 수에 따른 재킷원형 개발 제1보 \\ - 여유분을 중심으로 -} \\ 김 명 옥·김 경 아 \\ 호원대학교 패션디자인학과, 명지전문대학 패션텍스타일세라믹과*
}

\begin{abstract}
This study aims to suggest the proper ease for slim-fit jackets according to the number of buttons from a one-button jacket to four-button jackets for men in their 30's. The researchers carried out both an appearance evaluation and movement functionality evaluation. The results are as follows: When conducting the appearance evaluations, meaningful differences were found. The one-button jacket showed high scores for the $7.5 \mathrm{~cm}$ ease. The two-button jacket and the three-button jacket showed high scores for the $10.5 \mathrm{~cm}$ ease. The four-button jacket showed a high score for the $13.5 \mathrm{~cm}$ ease. Next, the results of the movement functionality evaluation showed the same trend; as the ease was increased from $7.5 \mathrm{~cm}$ to $13.5 \mathrm{~cm}$, the scores increased. This is because if the garments offer more ease, this gives room for actions. Additionally, it showed that if there were fewer jacket buttons, then the results showed a high score. The researchers believe that if the number of jacket buttons is lower, then the area of the V-zone increases, so that there is more room for movement. The study suggests a proper chest ease of $7.5 \mathrm{~cm}$ for the one-button jacket, $10.5 \mathrm{~cm}$ for the two-button jacket and three-button jacket, and $13.5 \mathrm{~cm}$ for the four-button jacket, respectively.
\end{abstract}

Keywords: men's wear(남성복), jacket(재킷), patternmaking(패턴설계), ease(여유분)

\section{Introduction}

외모와 패션에 관심이 많은 현대 남성소비자로 인하여 21세기 이후 남성복은 많은 발전을 거듭하 면서 여성복 시장규모를 앞서 가며 패션산업에서
차지하는 비중이 높아지고 있으며, 남성복에 대한 관심도 꾸준히 높아지고 있다. 특히 남성복시장에서 재킷은 수트의 상의로써 비즈니스웨어에서 매우 중 요한 역할을 담당하고 있으며, 사이즈 면에서 넉넉 하고 여유가 있는 클래식 핏 스타일과 사이즈가 슬

Received 29 July 2015, revised 5 September 2015, accepted 8 September 2015.

${ }^{+}$Corresponding author (kkakdk@hanmail.net) 
림하여 착용자의 신체에 밀착되는 슬림 핏으로 구 별되어 판매되고 있다. 슬림 핏 재킷은 10 여 년 전 부터 소개되어 착용되어 왔으며, 20대부터 슬림 핏 스타일을 선호하며 착용해오던 기존의 소비자들은 30 대가 되면서 20 대와는 달라진 허리둘레를 중심으 로 둘레항목이 증가한 체형특징을 나타내고 있다. 하지만 대부분의 남성복 제조업자들은 20 대 이상적 인 체형의 모델을 기용함으로써 30대 남성체형 특징 을 반영하지 못하고 남성복을 제작하고 있다(Kim,

Kim \& Suh, 2012).

의복에서 여유분이란 인체와 의복사이의 공간으 로 인간이 의복착용 시 느끼는 착용감에 매우 큰 영 향을 미치는 요소이다. 일반적으로 여유분은 의복착 용 시의 여유분과 디자인상 여유분의 두 가지 형태 로 나뉜다. 의복착용 시 여유분이란 의복의 편안함 과 움직임 및 드레이프성을 주기 위해 신체치수에 더해지는 옷감의 양(amount)이며, 디자인상 여유분 이란 의복의 구성선이나 형태의 변화에 의해 특정 한 디자인 효과를 얻고자 더해지는 추가적인 옷감 의 양을 의미한다(Petrova \& Asdown, 2008). 본 연 구에서는 의복착용 시의 여유분에 한하여 논의하고 자 한다.

재킷은 일반적으로 셔츠 위에 착용되는 옷으로 여유분을 얼마로 설정하는 지가 재킷패턴 설계 시 매우 중요한 변수이다. 또한 재킷의 전형적인 디자 인은 패션 트렌드에 따라 1 버튼 재킷, 2 버튼 재킷, 3 버튼 재킷, 4 버튼 재킷과 같이 1 버튼 재킷에서 4 버 튼 재킷 등으로 디자인이 변화한다. 여기에서 재킷 의 버튼 수가 변화되면, 재킷의 앞중심 부위인 브이 존(V-zone)의 영역이 변화되며, 브이존이 변화되면 재킷패턴 설계 시 뒷목너비와 앞목너비의 관계 또 한 변화된다. 또한 선행연구(Kim et al., 2012)의 남 성복 재킷 제조업체 실태조사에 따르면 재킷의 버 튼 수에 따라 뒷목너비와 앞목너비가 변화하며, 이 와 함께 둘레항목의 여유분 또한 달라지는 것을 알 수 있었다.

남성복시장의 활성화로 남성복에 대한 연구(Kim \& Jo, 2006; Kim, Kim \& Park, 2014; Kim \& Lee, 2004; Kim \& Suh, 2011)가 활발하게 진행되어 오고 있지만, 30 대 남성 체형특성을 반영하면서 슬림 핏 스타일에 재킷의 전형적인 디자인인 1 버튼 재킷, 2
버튼 재킷, 3 버튼 재킷 등과 같은 재킷의 여밈 버튼 수에 따라 변화되는 재킷패턴의 여유분 변화에 대 한 연구는 미비하다. 그러므로 30 대의 체형변화를 고려하면서 슬림 핏 재킷패턴 제작 시의 소요시간 을 단축하고, 다양한 디자인으로 변형이 가능한 30 대 남성 표준체형의 슬림 핏 재킷패턴의 버튼 수에 따른 적정 여유분을 규명하는 연구가 필요한 실정 이다.

따라서 본 연구에서는 30 대 남성 슬림 핏 재킷의 1 버튼 재킷에서 4 버튼 재킷까지의 재킷의 버튼 수 에 따른 슬림 핏 재킷의 적정 여유분을 알아보고자 하며, 이 결과를 토대로 남성복 제조업체에게 재킷 패턴 제작 시 과학적이고 실질적인 데이터를 제공 하고자 한다.

\section{Research Methodology}

\section{Selection of subjects}

남성복 재킷의 버튼 수에 따른 적정 여유분 설정 을 위해 선정한 피험자 신체치수는 제 5 차 한국인 인 체치수조사의 자료를 기준으로 하였다(Korean Agency for Technology and Standards, 2005). 30 39세 남성 표준치수의 표준편차 오차범위 안에서 피험자 6 명 을 선정하였으며, 피험자들의 신체측정치수는 〈Table $1\rangle$ 과 같다.

\section{Experimental jacket designs}

슬림 핏 재킷의 버튼 수에 따른 적정 여유분을 알 아보기 위한 실험복 디자인은 〈Fig. 1>과 같다. 그림 에서와 같이, 소비자 선호도와 의류제조업체 현황조 사를 바탕으로 하여 뒤프린세스라인에 트임이 있는 테일러드 재킷으로 하였다. 다만 앞목너비의 변화도 여유분 설정에 영향을 미치므로, 이에 대한 영향을 배제하기 위해 테일러드 재킷 구성요소에서 고지라 인에서 연결된 윗칼라(upper collar)가 없이 라펠만 있는 테일러드 재킷으로 하였다.

\section{Experimental jackets patternmaking and} manufacturing

버튼 수 변화에 따른 여유분 설정단계는 선행연 구(Kim \& Lee, 2004)와 남성복 제조업체의 실태조 


\begin{tabular}{|c|c|c|c|c|c|c|c|c|}
\hline \multirow[t]{2}{*}{ Body areas } & \multicolumn{6}{|c|}{ Subjects } & \multicolumn{2}{|c|}{$\begin{array}{l}\text { Standard body type } \\
\text { of men in their 30's } \\
\qquad(\mathrm{N}=710)\end{array}$} \\
\hline & A & $\mathrm{B}$ & $\mathrm{C}$ & $\mathrm{D}$ & E & $\mathrm{F}$ & Mean & S.D. \\
\hline Stature & 173.4 & 174.0 & 173.0 & 171.0 & 175.0 & 171.2 & 171.0 & 5.6 \\
\hline Weight & 73.0 & 71.2 & 72.0 & 69.0 & 74.2 & 72.5 & 71.9 & 9.7 \\
\hline Chest circumference & 97.5 & 95.5 & 98.5 & 97.5 & 97.0 & 95.0 & 97.5 & 5.8 \\
\hline Waist circumference & 85.2 & 82.2 & 83.5 & 83.5 & 81.5 & 84.5 & 83.8 & 7.6 \\
\hline Hip circumference & 96.5 & 94.0 & 97.5 & 96.0 & 97.5 & 96.5 & 95.3 & 5.4 \\
\hline Armhole length & 43.5 & 44.1 & 43.8 & 44.0 & 43.8 & 45.0 & 43.6 & 2.9 \\
\hline Upper arm circumference & 30.0 & 28.8 & 32.0 & 30.8 & 29.5 & 31.1 & 30.7 & 2.5 \\
\hline Wrist circumference & 17.1 & 16.0 & 16.2 & 16.4 & 16.0 & 17.0 & 16.8 & 0.9 \\
\hline Waist back length & 43.0 & 43.2 & 43.5 & 43.5 & 44.5 & 42.5 & 42.8 & 3.0 \\
\hline Waist front length & 38.0 & 38.5 & 40.2 & 39.0 & 41.0 & 38.5 & 35.7 & 3.1 \\
\hline Biacromion length & 43.8 & 43.0 & 44.5 & 44.1 & 43.0 & 43.0 & 43.6 & 2.6 \\
\hline Front interscye & 37.0 & 36.0 & 36.5 & 37.0 & 37.5 & 36.5 & 36.6 & 2.1 \\
\hline Back interscye & 41.5 & 40.0 & 39.8 & 41.8 & 39.5 & 39.0 & 41.0 & 2.8 \\
\hline Arm length & 58.2 & 57.5 & 57.5 & 58.0 & 57.8 & 57.0 & 57.6 & 2.6 \\
\hline
\end{tabular}

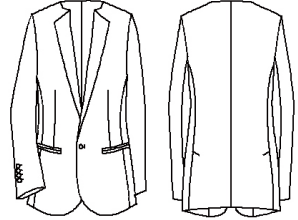

1-Button Jacket

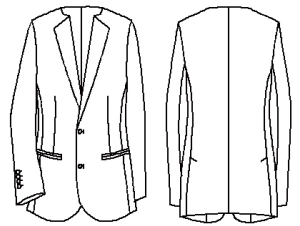

2-Button Jacket

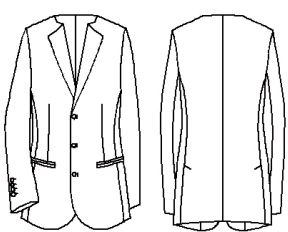

3-Button Jacket

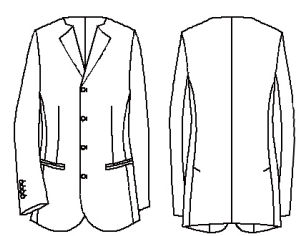

4-Button Jacket

〈Fig. 1〉 Experimental jacket designs according to numbers of jacket buttons

사 결과(Kim et al., 2012)를 바탕으로 설정하였다. 실험복의 각 단계별 치수는 선행연구 및 캐릭터캐 주얼 존과 신사정장 존에서 제작되고 있는 슬림 핏 재킷패턴 사이즈 평균값을 기준으로 하여 부위에 따라 조절하였다. 즉, 가슴둘레 $+10.5 \mathrm{~cm}$, 허리둘레+ $13.5 \mathrm{~cm}$, 엉덩이둘레 $+12 \mathrm{~cm}$ 를 기준으로 하여 여유분 의 단계를 3 단계로 하여 각 단계의 편차는 $\pm 3 \mathrm{~cm}$ 로 설정하였다. 가슴둘레, 허리둘레, 엉덩이둘레 여유 분을 제외한 뒷목너비, 앞목너비, 겨드랑앞벽사이길 이, 겨드랑뒤벽사이길이, 진동깊이 등 나머지 부위 의 치수는 조사대상 브랜드 실태조사 결과 $(\mathrm{Kim}$ et al., 2012)의 평균값을 참조하였다. 실태조사 결과에
서 앞목너비는 재킷의 버튼 수에 따라 변화가 있었 으나, 여유분 설정과 앞목너비 설정을 동시에 적용 하기에 변수가 너무 많은 관계로, 본 연구에서는 여 유분을 제외한 나머지 부위는 통제하여 모든 실험 복에 동일하게 적용하였다. 또한 목옆점에서 라펠꺾 임시작점까지의 치수는 버튼 수에 따라 30.3 44.5 $\mathrm{cm}$ 로 설정하였다.

재킷의 버튼 수에 따른 적정 여유분을 알아보기 위한 제도법은 본 연구의 선행연구(Kim \& Suh, 2014; $\mathrm{Kim}, 2015$ )인 4패널 재킷과 6패널 재킷의 제도법과 동일하며, 〈Fig. 2〉와 같다. 〈Fig. 2〉의 제도법을 기준 으로 재킷원형 패턴을 제도한 이후에 재킷의 버튼 


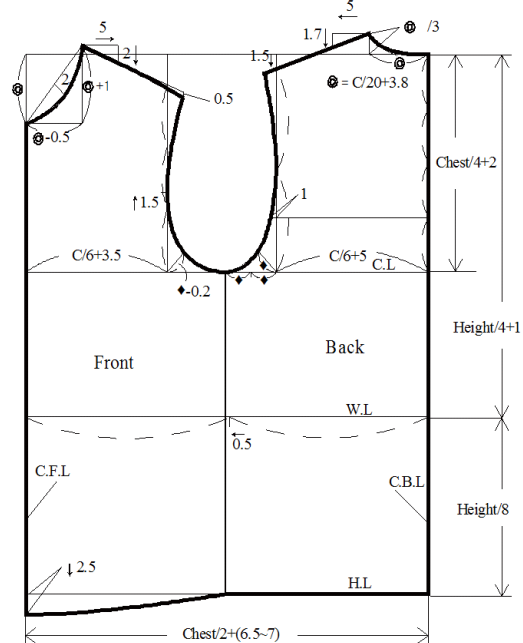

4-panel jacket sloper patternmaking

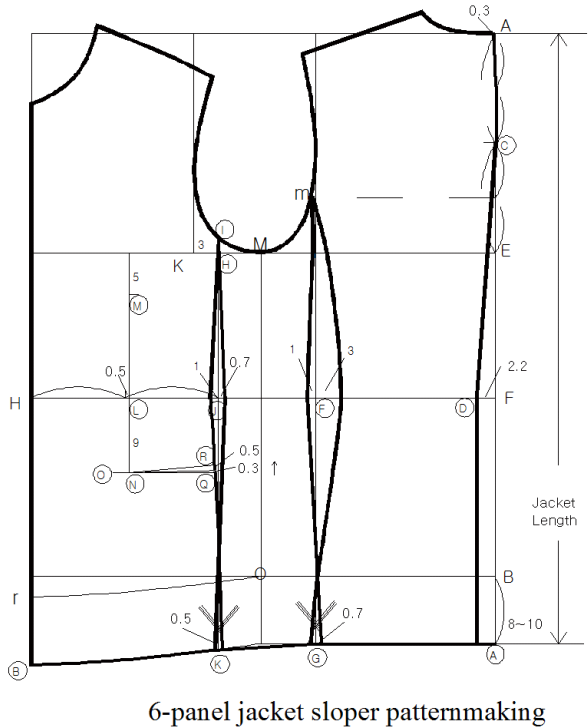

6-panel jacket sloper patternmaking

〈Fig. 2〉 Patternmaking methods of the 4-panel jacket and 6-panel jacket
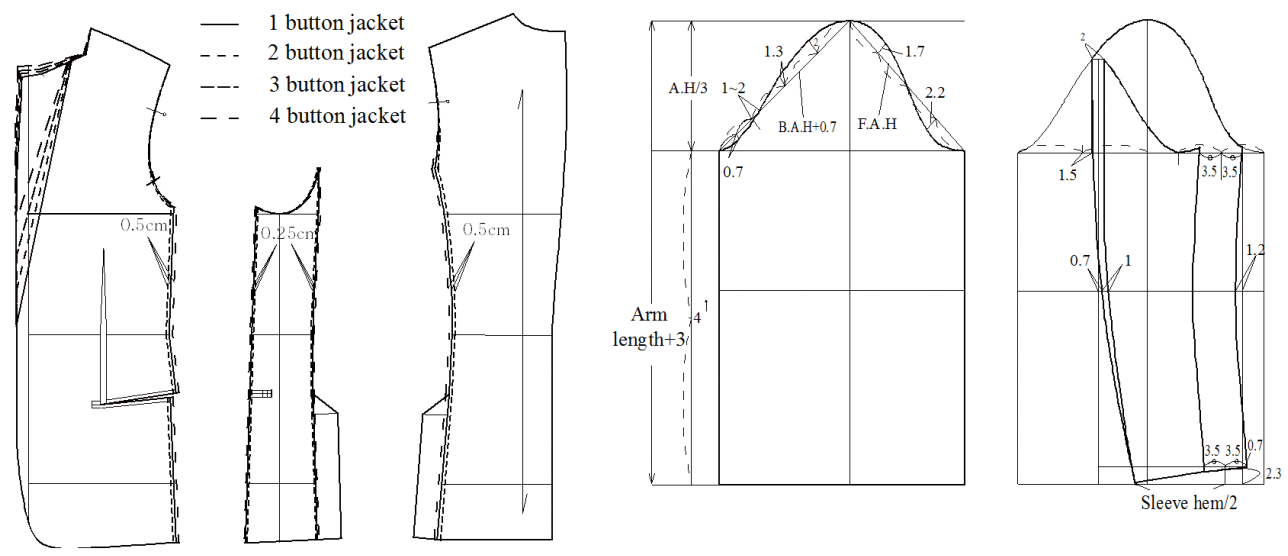

〈Fig. 3〉 Overlapped experimental jacket patterns and sleeve patternmaking

수에 따라 가슴둘레 여유분과 라펠꺾임 시작점의 위 치를 달리하여 12 벌의 재킷 실험복 패턴을 제도하 였다. 제도한 12 벌의 재킷패턴의 중합도와 소매패 턴 제도법은〈Fig. 3 과 같다.

\section{Materials of experimental jackets}

실험복 소재는 소비자의 선호도와 남성복 조사대 상 브랜드의 실태조사를 기준으로 하여 선정하였다.
겉감은 울 $100 \%$ 로 선정하였고, 안감은 폴리에스테 르 $100 \%$ 로 선정하였다. 실험복 소재의 물성은 한국 공업규격 $\mathrm{KS} \mathrm{K}$ 에 의하여 측정하였으며, 겉감 및 안 감의 구체적인 실험복 소재의 물성은〈Table 2〉와 같다.

\section{Evaluations}

실험복의 착의평가는 외관평가와 동작평가로 나 
〈Table 2〉 Properties of materials for experimental jackets

\begin{tabular}{c|c|c|c|c|c|c}
\hline & Fabric name & Fiber ${ }^{1)}$ & Weave & $\begin{array}{c}\text { Thickness }{ }^{2} \\
(\mathrm{~mm})\end{array}$ & $\begin{array}{c}\text { Density } \\
(\text { number/inch })\end{array}$ & $\begin{array}{c}\text { Weight }^{4)} \\
\left(\mathrm{g} / \mathrm{m}^{2}\right)\end{array}$ \\
\hline Outshell & Wool & W 100 & Twill & 0.43 & $67 \times 101$ & 193.8 \\
\hline Lining & Polyester & PET 100 & Plain & 0.08 & $102 \times 83$ & 61.9 \\
\hline
\end{tabular}

* Other materials: fusible interlining, armhole tape, $4 \mathrm{~mm}$ shoulder pad, sleeve head, buttons etc.

누어 실시하였다. 외관평가를 위한 평가항목은 선행 연구(Kim \& Lee, 2004; Uh, 2007)를 참조하여, 재킷 의 버튼 수에 따른 적정 여유분 평가에 대한 항목을 중심으로 전면 5항목, 측면 3항목, 후면 4항목 총 12 항목으로 구성하였다. 외관 평가단은 의복구성학 전 문지식이 있는 대학원 이상의 전문가집단 6 인으로 구성하여 매우 그렇다(5점)에서 매우 그렇지 않다(1 점)까지 5점 리커트 척도를 사용하였으며, 2회 반복 평가하였다. 동작평가를 위한 평가항목은 정립 시 착용감 6 항목과 동작 별 착용감 8 항목으로 총 14 항 목을 중심으로 평가하였다. 동작 평가단은〈Table $1>$ 에 제시한 피험자 6 명으로 구성되어 5점 척도를 사용하였으며, 1 회 평가 후 30 분간 휴식을 취한 후 다시 평가하여 총 2회 평가하였다.

\section{Results and Discussions}

\section{Results of appearance evaluation}

30 대 남성 표준체형 슬림 핏 재킷의 버튼 수에 따 른 적정 여유분을 알아보기 위한 12 벌 실험복의 외 관평가 결과는〈Table 3 과 같다. 외관평가를 위한 피험자는〈Table 1〉에 제시된 피험자 중 피험자 A 이며, 피험자의 착장사진은〈Fig. 4〉와 같다.

1 버튼 재킷에 대한 평가 결과, 전면과 측면 그리 고 후면의 12 개 항목 중 8 개 항목에서 유의차가 나 타났다. 전면에서는 여유분 $7.5 \mathrm{~cm}$ 와 $10.5 \mathrm{~cm}$ 인 실험 복이 앞품, 브이존, 가슴, 허리 등의 부위에서 좋은 결과를 나타냈다. $7.5 \mathrm{~cm}$ 와 $10.5 \mathrm{~cm}$ 실험복이 각각 최 고점을 획득한 부위는 2개씩 서로 동일하였으며, 던 컨테스트 결과도 두 실험복은 동일한 a그룹으로 분 류되어 큰 차이는 나타나지 않았다. 측면에서는 여 유분 $7.5 \mathrm{~cm}$ 인 실험복이 가슴부위와 허리부위에서 유의하게 높은 점수를 받았다. 후면에서는 여유분
$7.5 \mathrm{~cm}$ 실험복이 뒤품부위에서, 여유분 $10.5 \mathrm{~cm}$ 인 실 험복은 허리부위에서 유의하게 높은 것으로 나타났 다. 이상의 결과를 평균값으로 종합하면, 1 버튼 재 킷은 여유분 $7.5 \mathrm{~cm}$ 인 실험복이 3.88 점, $10.5 \mathrm{~cm}$ 인 실 험복은 3.85 점, 여유분 $13.5 \mathrm{~cm}$ 인 실험복은 3.06 점의 순으로 우수한 것을 알 수 있었다.

2 버튼 재킷에 대한 평가 결과, 전면과 측면 그리 고 후면의 12 개 항목 중 7 개 항목에서 유의차가 나 타났다. 전면에서는 허리와 엉덩이부위에서 유의한 차가 나타났으며, 여유분 $10.5 \mathrm{~cm}$ 인 실험복이 가장 높 은 점수를 받은 것으로 나타났다. 측면에서는 가슴, 허리부위에서 여유분 $10.5 \mathrm{~cm}$ 가 유의하게 높은 것으 로 나타났으며, 엉덩이부위는 여유분 $7.5 \mathrm{~cm}$ 와 $10.5 \mathrm{~cm}$ 인 실험복이 동일하게 높은 것으로 나타났다. 후면 에서는 허리부위에서 여유분 $10.5 \mathrm{~cm}$ 인 실험복이 유 의하게 가장 높은 점수를 획득하였으며, 엉덩이부위 에서는 여유분 $10.5 \mathrm{~cm}$ 와 $13.5 \mathrm{~cm}$ 인 실험복이 동일하 게 높은 것으로 나타났다. 이상의 결과를 평균값으 로 종합하면, 2 버튼 재킷은 여유분 $10.5 \mathrm{~cm}$ 인 실험복 은 4.02 점, $7.5 \mathrm{~cm}$ 인 실험복은 3.30 점, $13.5 \mathrm{~cm}$ 인 실험 복은 3.24점의 순으로 우수한 것을 알 수 있었다.

3 버튼 재킷에 대한 평가 결과, 전면과 측면 그리 고 후면의 12 개 항목 중 9 개 항목에서 유의차가 나 타났다. 전면에서는 앞품, 브이존(V-zone), 가슴, 허 리, 엉덩이 등 모든 부위에서 $10.5 \mathrm{~cm}$ 여유분량이 유 의하게 높은 점수를 얻었다. 측면에서는 허리부위에 서 $10.5 \mathrm{~cm}$ 인 실험복이 유의하게 높은 점수를 얻었 고, 엉덩이부위에서 여유분 $10.5 \mathrm{~cm}$ 와 $13.5 \mathrm{~cm}$ 가 동 일하게 높은 점수를 얻었다. 후면에서는 허리부위에 서 $10.5 \mathrm{~cm}$ 여유인 실험복이 유의하게 가장 높은 점수 를 얻었으며, 엉덩이부위는 여유분 $10.5 \mathrm{~cm}$ 와 $13.5 \mathrm{~cm}$ 가 동일하게 높은 점수를 얻었다. 이상의 결과를 평 균값으로 종합하면, 3 버튼 재킷은 여유분이 $10.5 \mathrm{~cm}$ 
실험복이 3.95점, $13.5 \mathrm{~cm}$ 실험복이 3.28 점, $7.5 \mathrm{~cm}$ 실 험복이 3.02점의 순으로 우수한 것을 알 수 있었다.

4 버튼 재킷 평가 결과, 전면과 후면의 12 개 항목 중 4 개 항목에서 유의차가 나타났다. 전면에서는 브 이존(V-zone), 허리, 엉덩이 부위에서 유의차가 나타 났는데, 여유분 $10.5 \mathrm{~cm}$ 와 $13.5 \mathrm{~cm}$ 실험복이 던컨테스 트 결과에서 동일한 a그룹으로 평가되었다. 측면에 서는 유의차가 없었지만, 여유분 $13.5 \mathrm{~cm}$ 실험복이 2 개 항목에서 가장 높은 점수를 얻었다. 후면에서는 엉덩이부위에서 $13.5 \mathrm{~cm}$ 여유분 실험복이 유의하게 높은 점수를 얻었으며. 여유분 $10.5 \mathrm{~cm}$ 실험복은 3 개 항목에서 유의한 차이는 없으나 높은 점수를 얻었 다. 4 버튼 재킷의 전반적인 외관평가는 1 버튼 재킷 에서 3 버튼 재킷까지의 버튼 수에 따른 외관 평가결 과와 비교 시 낮은 것으로 나타났다. 이러한 이유는
버튼 수가 증가하여 브이존 영역이 좁아져서 가슴 부위, 앞품부위, 뒤품부위, 허리부위 등을 중심으로 한 외관 평가결과가 떨어졌기 때문으로 사료된다. 이상의 결과를 평균값으로 종합하면, 여유분 $13.5 \mathrm{~cm}$ 실험복이 3.39점, $10.5 \mathrm{~cm}$ 실험복이 3.35 점, $7.5 \mathrm{~cm}$ 실 험복이 2.80점의 순으로 우수한 것을 알 수 있었다.

이상의 외관평가 결과를 종합해 보면, 1 버튼 재 킷은 가슴둘레 여유분이 $7.5 \mathrm{~cm}$ 인 실험복이, 2 버튼 재킷과 3 버튼 재킷은 가슴둘레 여유분이 $10.5 \mathrm{~cm}$ 인 실험복이, 4 버튼 재킷은 가슴둘레 여유분이 $13.5 \mathrm{~cm}$ 인 실험복이 가장 높은 점수를 얻었다. 이러한 이유 는 슬림 핏 재킷의 버튼 수에 따른 둘레항목의 여유 분이 외관평가 결과에 영향을 주기 때문으로 재킷 의 버튼 수가 증가할수록 라펠꺾임시작점의 위치가 높아지고, 브이존부위가 좁아지면서 재킷의 여밈이

〈Table 3〉 Appearance evaluations according to numbers of jacket buttons

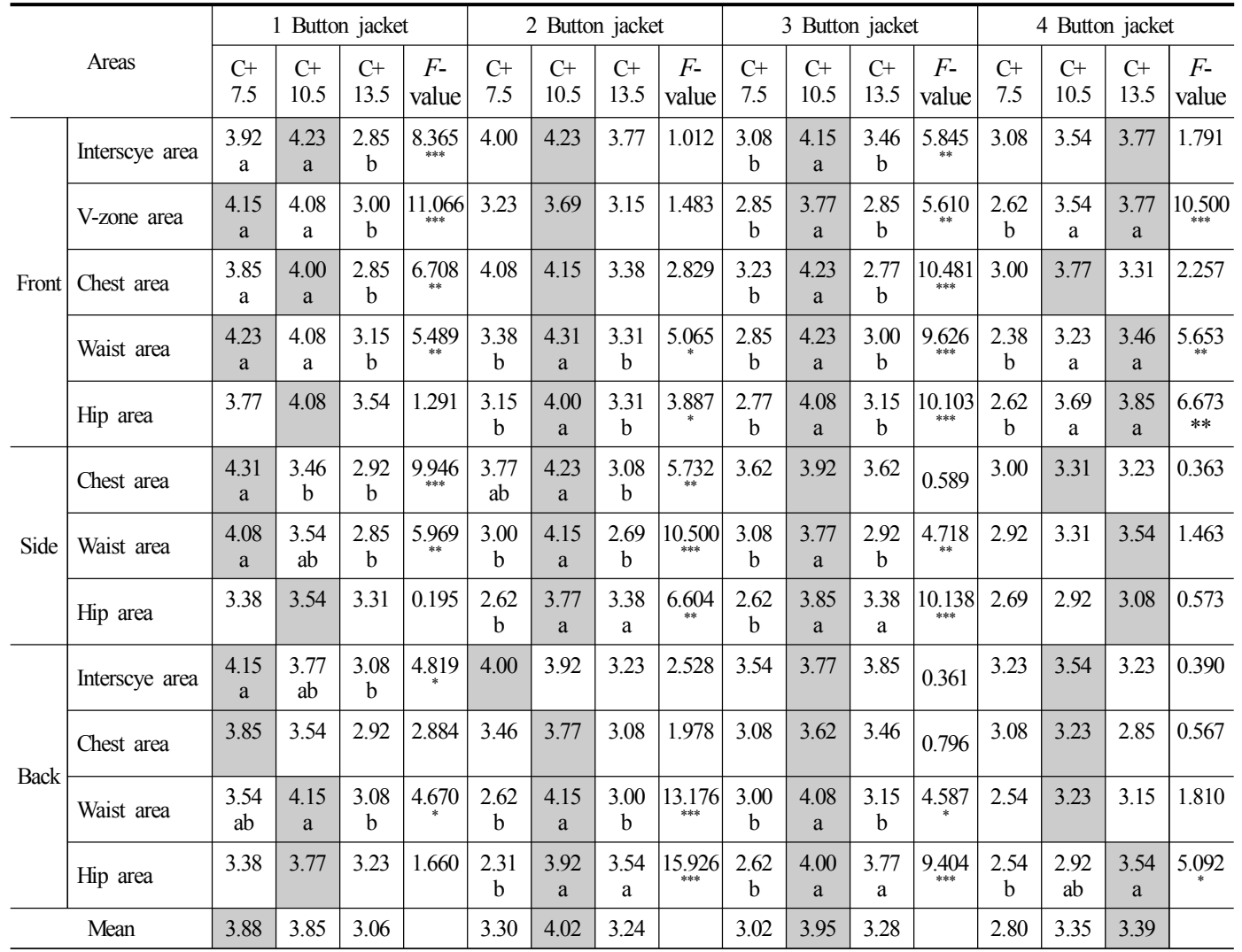

${ }^{*} \mathrm{C}=$ chest, 1 point: Never, 2 point: Not true, 3 point: Somewhat good, 4 point: True (good), 5 point: Very true (good) ${ }^{*} p<.05,{ }^{* *} p<.01,{ }^{* * *} p<.001$, Group by Duncan test: $\mathrm{a}>\mathrm{b}>\mathrm{c}$ 
채워짐으로 인해 더 많은 여유분이 필요함을 알 수 있었다. 따라서 재킷의 버튼 수에 따라 각 패턴에서 설계하여야 할 둘레항목의 적정한 여유분이 달라져 야함을 외관평가를 통하여 확인할 수 있었다.

\section{Movement functionality evaluation}

실험복의 동작기능성에 대한 평가 결과는〈Table $4>$ 와 같다. 실험복의 가슴둘레 여유분이 많을수록 대부분의 평가항목에서 동작기능성 평가 결과는 좋

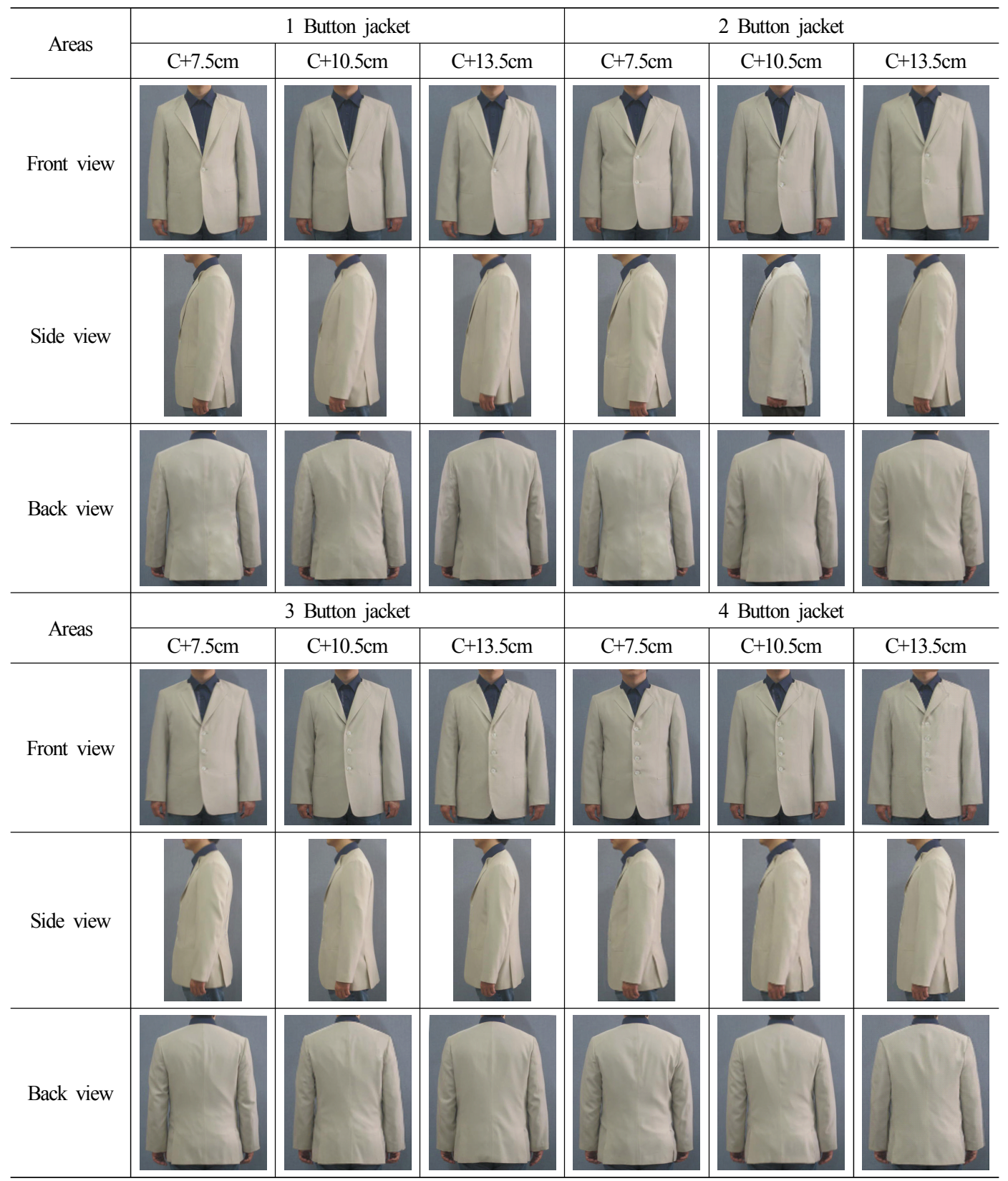

〈Fig. 4〉 Pictures of experimental jackets according to numbers of jacket buttons 
아지는 것으로 평가되었다.

1 버튼 재킷 평가 결과, 14 개 항목 중 8 개 항목에 서 유의차가 나타났다. 정립 시 착용감은 어깨부위 에서 여유분 $13.5 \mathrm{~cm}$ 인 실험복이 유의하게 높게 나타났 다. 앞품과 가슴부위에서는 여유분 $10.5 \mathrm{~cm}$ 와 $13.5 \mathrm{~cm}$ 인 실험복이 던컨테스트 결과에서 동일한 a그룹으로 평가되었다. 동작 시 착용감은 팔을 45 도 앞으로 들 었을 때, 옆으로 90 도 들 때, 팔을 최대한 들 때의 항목에서 $13.5 \mathrm{~cm}$ 여유분 실험복이 유의하게 높은 점수를 얻었으며, 팔을 90도로 들 때, 옆으로 45 도 들 때 항목에서 여유분 $10.5 \mathrm{~cm}$ 와 $13.5 \mathrm{~cm}$ 인 실험복 이 던컨테스트 결과에서 동일한 $\mathrm{a}$ 그룹으로 평가되
었다. 이상의 결과를 평균값으로 종합하면, 여유분 $13.5 \mathrm{~cm}$ 실험복이 3.93 점, $10.5 \mathrm{~cm}$ 실험복이 3.68 점, $7.5 \mathrm{~cm}$ 실험복이 3.22 점 순으로 우수한 것을 알 수 있었다.

2 버튼 재킷 평가 결과, 14 개 항목 중 5 개 항목에 서 유의차가 나타났다. 정립 시에는 유의차는 없었 으나, 앞품, 뒤품, 가슴, 허리, 엉덩이 부위 등에서 $13.5 \mathrm{~cm}$ 여유분 실험복이 가장 좋은 점수를 얻었다. 동작 시에는 팔을 45 도 앞으로 들었을 때, 옆으로 45도 들 때, 옆으로 90도 들 때, 팔을 최대한 들 때, 최대한 구부릴 때 등에서 여유분 $13.5 \mathrm{~cm}$ 실험복이 유의하게 높은 점수를 얻었다. 이상의 결과를 평균

〈Table 4〉 Movement functionality evaluations according to numbers of jacket buttons

$(N=12)$

\begin{tabular}{|c|c|c|c|c|c|c|c|c|c|c|c|c|c|c|c|c|c|}
\hline \multirow{2}{*}{ 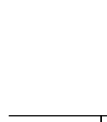 } & \multirow{2}{*}{ Areas } & \multicolumn{4}{|c|}{1 Button jacket } & \multicolumn{4}{|c|}{2 Button jacket } & \multicolumn{4}{|c|}{3 Button jacket } & \multicolumn{4}{|c|}{4 Button jacket } \\
\hline & & $\begin{array}{l}\mathrm{C}+ \\
7.5\end{array}$ & $\begin{array}{c}\mathrm{C}+ \\
10.5\end{array}$ & $\begin{array}{c}\mathrm{C}+ \\
13.5\end{array}$ & $\begin{array}{c}F- \\
\text { value }\end{array}$ & $\begin{array}{l}\mathrm{C}+ \\
7.5\end{array}$ & $\begin{array}{c}\mathrm{C}+ \\
10.5\end{array}$ & $\begin{array}{c}\mathrm{C}+ \\
13.5\end{array}$ & $\begin{array}{c}F- \\
\text { value }\end{array}$ & $\begin{array}{l}\mathrm{C}+ \\
7.5\end{array}$ & $\begin{array}{c}\mathrm{C}+ \\
10.5\end{array}$ & $\begin{array}{c}\mathrm{C}+ \\
13.5\end{array}$ & $\begin{array}{c}F- \\
\text { value }\end{array}$ & $\begin{array}{l}\mathrm{C}+ \\
7.5\end{array}$ & $\begin{array}{c}\mathrm{C}+ \\
10.5\end{array}$ & $\begin{array}{c}\mathrm{C}+ \\
13.5\end{array}$ & $\begin{array}{c}F- \\
\text { value }\end{array}$ \\
\hline \multirow{6}{*}{ Standing } & Shoulder & $\begin{array}{c}3.55 \\
\mathrm{~b}\end{array}$ & $\begin{array}{c}3.82 \\
\mathrm{ab}\end{array}$ & $\begin{array}{c}4.18 \\
\mathrm{a}\end{array}$ & 2.403 & 3.36 & 3.91 & 3.91 & 2.000 & 3.27 & 3.55 & 3.82 & 1.484 & $\begin{array}{c}2.82 \\
b\end{array}$ & $\begin{array}{c}3.27 \\
\mathrm{ab}\end{array}$ & $\begin{array}{c}3.73 \\
\mathrm{a}\end{array}$ & 4.870 \\
\hline & Front interscye & $\begin{array}{c}3.64 \\
\mathrm{~b}\end{array}$ & $\begin{array}{c}4.18 \\
\mathrm{a}\end{array}$ & $\begin{array}{c}4.27 \\
\mathrm{a}\end{array}$ & $\underset{*}{4.674}$ & 3.55 & 3.73 & 3.91 & 0.550 & 3.36 & 3.64 & 3.91 & 1.116 & $\begin{array}{c}2.45 \\
\mathrm{~b}\end{array}$ & $\begin{array}{c}3.00 \\
\mathrm{ab}\end{array}$ & $\begin{array}{c}3.64 \\
\mathrm{a}\end{array}$ & 5.721 \\
\hline & Back interscye & 3.27 & 3.82 & 4.09 & 3.058 & 3.09 & 3.27 & 3.91 & 2.343 & 2.73 & 3.27 & 3.82 & 2.134 & $\begin{array}{c}2.27 \\
b\end{array}$ & $\begin{array}{c}2.82 \\
\mathrm{ab}\end{array}$ & $\begin{array}{c}3.55 \\
\mathrm{a}\end{array}$ & 4.405 \\
\hline & Chest & $\begin{array}{c}3.64 \\
b\end{array}$ & $\begin{array}{c}4.27 \\
\mathrm{a}\end{array}$ & $\begin{array}{c}4.36 \\
\mathrm{a}\end{array}$ & 4.597 & 3.27 & 3.55 & 4.18 & 3.185 & $2.91 b$ & $\begin{array}{c}3.82 \\
\mathrm{a}\end{array}$ & $\begin{array}{c}3.91 \\
\mathrm{a}\end{array}$ & 5.187 & $\begin{array}{c}2.55 \\
\mathrm{~b}\end{array}$ & $\begin{array}{c}3.27 \\
\mathrm{a}\end{array}$ & $\begin{array}{c}3.73 \\
\mathrm{a}\end{array}$ & 6.143 \\
\hline & Waist & 4.10 & 4.45 & 4.36 & 1.161 & 3.73 & 4.00 & 4.27 & 1.337 & 3.36 & 3.82 & 4.00 & 1.598 & 3.09 & 3.36 & 3.81 & 2.112 \\
\hline & Hip & 4.36 & 4.36 & 4.64 & 1.071 & 4.09 & 4.09 & 4.27 & 0.260 & 3.91 & 4.00 & 4.18 & 0.343 & 3.45 & 3.64 & 4.18 & 2.063 \\
\hline \multirow{8}{*}{ Actions } & Walk slightly & 3.82 & 4.00 & 4.18 & 0.968 & 3.36 & 3.73 & 3.82 & 0.854 & 3.27 & 3.64 & 3.82 & 1.38 & $\begin{array}{c}2.55 \\
\mathrm{~b}\end{array}$ & $\begin{array}{c}3.27 \\
\mathrm{ab}\end{array}$ & $\begin{array}{c}3.73 \\
\mathrm{a}\end{array}$ & $\underset{*}{4.674}$ \\
\hline & $\begin{array}{l}\text { Raise arms } \\
\text { forward } 45^{\circ} \text { up }\end{array}$ & $\begin{array}{c}2.91 \\
\mathrm{~b}\end{array}$ & $\begin{array}{c}3.45 \\
\mathrm{ab}\end{array}$ & $\begin{array}{c}3.73 \\
\mathrm{a}\end{array}$ & 3.621 & $\begin{array}{c}2.82 \\
\mathrm{~b}\end{array}$ & $\begin{array}{c}3.00 \\
\mathrm{~b}\end{array}$ & $\begin{array}{c}3.73 \\
\mathrm{a}\end{array}$ & $\underset{*}{3.853}$ & 2.73 & 3.18 & 3.45 & 1.561 & $\begin{array}{c}2.36 \\
b\end{array}$ & $\begin{array}{c}2.73 \\
\mathrm{ab}\end{array}$ & $\begin{array}{c}3.27 \\
\mathrm{a}\end{array}$ & 5.352 \\
\hline & $\begin{array}{l}\text { Raise arms } \\
90^{\circ} \text { up }\end{array}$ & $\begin{array}{c}2.09 \\
b\end{array}$ & $\begin{array}{c}2.82 \\
\mathrm{a}\end{array}$ & $\begin{array}{c}3.18 \\
\mathrm{a}\end{array}$ & 6.292 & 2.09 & 2.27 & 3.00 & 3.043 & 2.00 & 2.27 & 2.82 & 1.921 & $\begin{array}{c}1.64 \\
\mathrm{~b}\end{array}$ & $\begin{array}{c}2.09 \\
\mathrm{ab}\end{array}$ & $\begin{array}{c}2.45 \\
\mathrm{a}\end{array}$ & 4.552 \\
\hline & $\begin{array}{l}\text { Raise arms } \\
\text { sideward } 45^{\circ} \text { up }\end{array}$ & $\begin{array}{c}3.00 \\
\mathrm{~b}\end{array}$ & $\begin{array}{c}3.64 \\
\mathrm{a}\end{array}$ & $\begin{array}{c}3.82 \\
\mathrm{a}\end{array}$ & 7.444 & $\begin{array}{c}2.91 \\
\mathrm{~b}\end{array}$ & $\begin{array}{c}3.36 \\
\mathrm{ab}\end{array}$ & $\begin{array}{c}3.82 \\
\mathrm{a}\end{array}$ & 5.208 & $\begin{array}{c}2.82 \\
b\end{array}$ & $\begin{array}{c}3.27 \\
\mathrm{ab}\end{array}$ & $\begin{array}{c}3.82 \\
\mathrm{a}\end{array}$ & 6.149 & $\begin{array}{c}2.64 \\
b\end{array}$ & $\begin{array}{c}2.91 \\
\mathrm{~b}\end{array}$ & $\begin{array}{c}3.36 \\
\mathrm{a}\end{array}$ & 7.424 \\
\hline & $\begin{array}{l}\text { Raise arms } \\
\text { sideward } 90^{\circ} \text { up }\end{array}$ & $\begin{array}{c}2.73 \\
b\end{array}$ & $\begin{array}{c}3.27 \\
\mathrm{ab}\end{array}$ & $\begin{array}{c}3.64 \\
\mathrm{a}\end{array}$ & 4.634 & $\begin{array}{c}2.55 \\
\mathrm{~b}\end{array}$ & $\begin{array}{c}2.91 \\
\mathrm{ab}\end{array}$ & $\begin{array}{c}3.45 \\
\mathrm{a}\end{array}$ & $\underset{*}{4.222}$ & 2.64 & 3.00 & 3.36 & 2.553 & $\begin{array}{c}1.91 \\
\mathrm{~b}\end{array}$ & $\begin{array}{c}2.73 \\
\mathrm{a}\end{array}$ & $\begin{array}{c}3.09 \\
\mathrm{a}\end{array}$ & 15.144 \\
\hline & $\begin{array}{l}\text { Raise arms } \\
\text { maximum up }\end{array}$ & $\begin{array}{c}2.36 \\
b\end{array}$ & $\begin{array}{c}2.82 \\
\mathrm{ab}\end{array}$ & $\begin{array}{c}3.36 \\
\mathrm{a}\end{array}$ & 4.417 & $\begin{array}{c}1.91 \\
\mathrm{~b}\end{array}$ & $\begin{array}{c}2.64 \\
\mathrm{ab}\end{array}$ & $\begin{array}{c}3.27 \\
\mathrm{a}\end{array}$ & 5.993 & 2.09 & 2.55 & 2.91 & 2.259 & $\begin{array}{c}1.55 \\
b\end{array}$ & $\begin{array}{c}2.55 \\
\mathrm{a}\end{array}$ & $\begin{array}{c}2.91 \\
\mathrm{a}\end{array}$ & 8.960 \\
\hline & $\begin{array}{l}\text { Bend down } \\
\text { maximum }\end{array}$ & 2.55 & 3.00 & 3.36 & 1.894 & $\begin{array}{c}2.45 \\
\mathrm{~b}\end{array}$ & $\begin{array}{c}3.09 \\
\mathrm{ab}\end{array}$ & $\begin{array}{c}3.45 \\
\mathrm{a}\end{array}$ & 3.470 & 2.45 & 2.82 & 3.36 & 2.235 & 2.15 & 2.91 & 3.00 & 2.325 \\
\hline & Sit on a chair & 3.09 & 3.64 & 3.91 & 3.118 & 3.00 & 3.36 & 3.73 & 2.609 & 2.82 & 3.55 & 3.73 & 2.500 & $\begin{array}{c}2.73 \\
b\end{array}$ & $\begin{array}{c}3.18 \\
\mathrm{ab}\end{array}$ & $\begin{array}{c}3.64 \\
\mathrm{a}\end{array}$ & $\underset{*}{3.348}$ \\
\hline & Mean & 3.22 & 3.68 & 3.93 & & 3.01 & 3.35 & 3.76 & & 2.88 & 3.31 & 3.63 & & 2.44 & 2.98 & 3.43 & \\
\hline
\end{tabular}

${ }^{*} \mathrm{C}=$ chest, 1 point: Never, 2 point: Not true, 3 point: Somewhat good, 4 point: True (good), 5 point: Very true (good). ${ }^{*} p<.05,{ }^{* *} p<.01,{ }^{* * *} p<.001$, Group by Duncan test: $\mathrm{a}>\mathrm{b}>\mathrm{c}$ 
값으로 종합하면, 여유분 $13.5 \mathrm{~cm}$ 실험복이 3.76점, $10.5 \mathrm{~cm}$ 실험복이 3.35 점, $7.5 \mathrm{~cm}$ 실험복이 3.01 점의 순으로 우수한 것을 알 수 있었다.

3 버튼 재킷 평가 결과, 14 개 항목 중 2 개 항목에 서 유의차가 나타났다. 정립 시는 가슴부위 항목에 서 유의한 차가 나타났으며, 여유분 $10.5 \mathrm{~cm}$ 와 $13.5 \mathrm{~cm}$ 인 실험복이 던컨테스트 결과에서 동일한 a그룹으 로 평가되었다. 동작 시에는 팔을 45 도 옆으로 들었 을 때의 항목에서 $13.5 \mathrm{~cm}$ 인 실험복이 유의하게 높 은 평가를 얻었다. 이상의 결과를 평균값으로 종합 하면, 여유분 $13.5 \mathrm{~cm}$ 실험복이 3.63 점, $10.5 \mathrm{~cm}$ 실험 복이 3.31 점, $7.5 \mathrm{~cm}$ 실험복이 2.88 점의 순으로 우수 한 것을 알 수 있었다.

4 버튼 재킷 평가 결과, 14 개 항목 중 11 개 항목에 서 유의차가 나타났다. 정립 시는 어깨, 앞품, 뒤품 부위에서 $13.5 \mathrm{~cm}$ 여유분 실험복이 유의하게 높은 점수를 얻었고, 가슴부위에서는 여유분 $10.5 \mathrm{~cm}$ 와 $13.5 \mathrm{~cm}$ 인 실험복이 던컨테스트 결과에서 동일한 a 그룹으로 평가되었다. 동작 시는 가볍게 걸었을 때 를 포함한 5 개 항목에서 여유분 $13.5 \mathrm{~cm}$ 실험복이 유의하게 높은 점수를 얻었고. 팔을 옆으로 90 도 들 때와 팔을 최대한 들 때 항목에서는 여유분 $10.5 \mathrm{~cm}$ 와 $13.5 \mathrm{~cm}$ 인 실험복이 던컨테스트 결과에서 동일한 $\mathrm{a}$ 그룹으로 평가되었다. 이상의 결과를 평균값으로 종 합하면, 여유분 $13.5 \mathrm{~cm}$ 실험복이 3.43 점, $10.5 \mathrm{~cm}$ 실 험복이 2.98 점, $7.5 \mathrm{~cm}$ 실험복이 2.44 점의 순으로 우 수한 것을 알 수 있었다.

이상의 동작평가 결과를 종합해 보면, 1 버튼 재 킷에서 4 버튼 재킷까지 가슴둘레 여유분 $13.5 \mathrm{~cm}$ 인 실험복이 가장 좋은 평가를 받았으며, 그 다음으로 는 가슴둘레 여유분 $10.5 \mathrm{~cm}$ 인 실험복, 가슴둘레 여 유분 $7.5 \mathrm{~cm}$ 인 실험복 순으로 좋은 평가를 받았다. 정립 시 보다는 동작 시 유의한 차이가 많은 것으로 나타났다. 재킷의 버튼 수가 증가할수록 동일한 여 유분일 때 동작평가 결과는 좋지 않은 것을 알 수 있었으며, 동일한 평가항목에서는 가슴둘레 여유분 이 많을수록 동작평가 결과가 좋음을 알 수 있었다.

\section{Suggested ease according to numbers of} jacket buttons

30 대 남성 표준체형의 버튼 수에 따른 슬림 핏 재
킷의 적정 여유분을 제시하기 위한 실험복의 외관 평가와 동작평가 결과를 종합적으로 비교분석 하였 다. 외관을 중요시 하는 슬림 핏 재킷의 특성을 반영 하여 전문가 그룹에서 논의하여 제안하는 재킷의 적정 여유분은 다음과 같다. 1 버튼 재킷은 가슴둘레 여유분 $7.5 \mathrm{~cm}$ 를, 2 버튼 재킷과 3 버튼 재킷은 가슴둘 레 여유분 $10.5 \mathrm{~cm}$ 를, 4 버튼 재킷은 가슴둘레 여유분 $13.5 \mathrm{~cm}$ 를 적정 여유분으로 제안하였다. 본 연구에 서 제안하는 버튼 수에 따른 슬림 핏 재킷의 부위별 여유분과 패턴치수에 대한 종합적인 결과와 슬림 핏 재킷을 제조하는 남성복 16 개 브랜드의 실태조 사 선행연구(Kim et al., 2012)에서 나타난 캐릭터캐 주얼과 신사정장 존에서 사용하고 있는 슬림 핏 재 킷의 부위별 여유분과 패턴치수를 비교분석한 결과 는 〈Table 5〉와 같다. 여유분은 각 브랜드 존에서 기 준으로 하는 신체사이즈와 패턴사이즈와의 차이를 계산한 값이다.

연구용 1 버튼 재킷 여유분은 가슴둘레 $7.5 \mathrm{~cm}$, 허 리둘레 $10.5 \mathrm{~cm}$, 엉덩이둘레 $9 \mathrm{~cm}$ 로, 가슴둘레는 캐 릭터캐주얼의 $7.4 \mathrm{~cm}$ 여유분과 동일하였으며 신사정 장의 $11.9 \mathrm{~cm}$ 보다는 다소 적은 것으로 나타났다. 허 리둘레는 연구용이 $10.5 \mathrm{~cm}$ 이었으며, 캐릭터캐주얼 의 $12.4 \mathrm{~cm}$ 보다는 여유분이 적은 것을 알 수 있었다. 이러한 이유는 허리둘레가 증가한 30대 체형의 특 징으로 인해 상대적으로 허리여유분이 줄어든 것으 로 판단된다. 엉덩이둘레의 여유분은 연구용이 $9 \mathrm{~cm}$, 캐릭터캐주얼이 $8.9 \mathrm{~cm}$, 신사정장이 $10.0 \mathrm{~cm}$ 로 큰 차 이가 없는 것을 알 수 있었다.

연구용 2 버튼과 3 버튼 재킷 여유분은 가슴둘레 $10.5 \mathrm{~cm}$, 허리둘레 $13.5 \mathrm{~cm}$, 엉덩이둘레 $12 \mathrm{~cm}$ 로, 가 슴둘레는 캐릭터캐주얼의 $8.1 \mathrm{~cm}$ 와 $9 \mathrm{~cm}$ 여유분보다 는 많고, 신사정장의 $12.3 \mathrm{~cm}$ 와 $13.3 \mathrm{~cm}$ 보다는 다소 적은 것으로 나타났다. 허리둘레는 연구용이 $13.5 \mathrm{~cm}$ 이었으며, 캐릭터캐주얼의 $12.8 \mathrm{~cm}$ 및 $13.8 \mathrm{~cm}$ 와 유 사하였으며, 신사정장의 $14.9 \mathrm{~cm}$ 와 $15.7 \mathrm{~cm}$ 보다는 여 유분이 적은 것을 알 수 있었다. 엉덩이둘레의 여유분 은 연구용이 $12 \mathrm{~cm}$ 로, 캐릭터캐주얼의 $9.4 \mathrm{~cm}$ 와 $10.2 \mathrm{~cm}$, 신사정장의 $10.2 \mathrm{~cm}$ 와 $10.9 \mathrm{~cm}$ 보다 많은 것을 알 수 있었다.

연구용 4 버튼 재킷 여유분은 가슴둘레 $13.5 \mathrm{~cm}$, 허리둘레 $16.5 \mathrm{~cm}$, 엉덩이둘레 $15 \mathrm{~cm}$ 로, 가슴둘레는 
캐릭터캐주얼의 여유분 $10.1 \mathrm{~cm}$ 보다는 많고, 신사정 장의 $13.8 \mathrm{~cm}$ 와 유사한 것으로 나타났다. 허리둘레는 연구용이 $16.5 \mathrm{~cm}$ 이었으며, 캐릭터캐주얼의 $14.8 \mathrm{~cm}$ 보다는 다소 많으며, 신사정장의 $16.0 \mathrm{~cm}$ 와 유사한 것 을 알 수 있었다. 엉덩이둘레의 여유분은 연구용이 $15 \mathrm{~cm}$ 로, 캐릭터캐주얼의 $11.2 \mathrm{~cm}$, 신사정장의 $11.3 \mathrm{~cm}$ 보다 많은 것을 알 수 있었다.

이상과 같이, 재킷 여유분은 가슴둘레 여유분은 연구용 재킷은 $\mathrm{C}+7.5 \sim 13.5 \mathrm{~cm}$ 로 설정되었으며, 캐릭 터캐주얼 존이 $\mathrm{C}+7.4 \sim 10.1 \mathrm{~cm}$, 신사정장 존이 $\mathrm{C}+11.9$ $13.8 \mathrm{~cm}$ 로 나타났다. 즉, 캐릭터캐주얼 존은 20대 남 성을 타깃으로 하여 여유분이 $7.4 \sim 10.1 \mathrm{~cm}$ 로 비교적 적었으며, 신사정장 존은 30 대 남성을 타깃으로 하 여 여유분이 $11.9 \sim 13.8 \mathrm{~cm}$ 로 비교적 많은 것으로 판 단되며, 버튼 수에 따른 적정 여유분의 차이는 크지 않은 것으로 나타났다. 반면, 본 연구용 재킷은 가슴 둘레 여유분이 재킷의 버튼 수에 따라 $7.5 \sim 13.5 \mathrm{~cm}$ 로 제시되었는데, 이는 조사대상 브랜드의 여유분 범위보다 다소 큰 것으로 나타났다. 허리둘레 여유 분은 캐릭터캐주얼이 $12.4 \sim 14.8 \mathrm{~cm}$ 로 비교적 적었 고, 신사정장은 $14.6 ~ 16.0 \mathrm{~cm}$ 로 비교적 많았으며, 연 구용 재킷은 허리둘레 여유분이 $10.5 ~ 16.5 \mathrm{~cm}$ 로 나타났 다. 엉덩이둘레 여유분은 캐릭터캐주얼이 $8.9 \sim 11.2 \mathrm{~cm}$, 신사정장도 $10.0 \sim 11.3 \mathrm{~cm}$ 로 브랜드 존에 따라 큰 차 이가 없는 반면, 연구용 재킷은 엉덩이둘레 여유분 이 9.0 15.0cm로 여유분 범위가 크며, 조사대상 브 랜드와는 차이가 있는 것으로 나타났다.

\section{Summary and Conclusion}

본 연구는 30대 남성 표준체형 슬림 핏 남성복의 1 버튼, 2 버튼, 3 버튼, 4 버튼 재킷의 버튼 수에 따른 적정 여유분을 알아보고자 여유분의 단계를 3 단계 로 설정하여, 12 벌의 실험복을 제작 후 외관평가와 동작평가를 실시하여 버튼 수에 따른 슬림 핏 재킷 의 적정 여유분을 규명하였다. 본 연구 결과의 요약 은 다음과 같다.

첫째, 재킷의 버튼 수에 따른 적정 여유분 설정을 위한 외관평가 결과, 1 버튼 재킷에서 4 버튼 재킷으 로 재킷의 버튼 수가 많을수록 가슴둘레 여유분량 이 많은 실험복이 외관평가가 더 좋은 것을 알 수 있었다. 즉, 1 버튼 재킷은 가슴둘레 여유분이 $7.5 \mathrm{~cm}$ 인 실험복이 가장 높은 점수를, 2 버튼 재킷과 3 버튼 재킷은 가슴둘레 여유분이 $10.5 \mathrm{~cm}$ 인 실험복이 각각 높은 점수를 얻었다. 4 버튼 재킷은 가슴둘레 여유분 이 $13.5 \mathrm{~cm}$ 인 실험복이 가장 좋은 결과를 나타냈다.

둘째, 재킷의 버튼 수에 따른 적정 여유분 설정을 위한 동작평가 결과, 재킷의 버튼 수와는 상관없이 실험복의 가슴둘레 여유분이 $7.5 \mathrm{~cm}$ 에서 $13.5 \mathrm{~cm}$ 로 점점 많을수록 대부분의 평가항목에서 동작평가 결 과는 좋아진 것으로 평가되었다. 즉, 1 버튼 재킷에서 4 버튼 재킷까지 가슴둘레 여유분 $13.5 \mathrm{~cm}$ 인 실험복 이 가장 좋은 평가를 받았으며, 그 다음으로는 가슴둘 레 여유분 $10.5 \mathrm{~cm}$ 인 실험복, 가슴둘레 여유분 $7.5 \mathrm{~cm}$ 인 실험복 순으로 좋은 평가를 받았다. 이러한 이유

〈Table 5〉 Comparisons: ease and pattern size of researcher's pattern vs. men's wear brands

(Unit: $\mathrm{cm}$ )

\begin{tabular}{c|l|c|c|c|c|c}
\hline \multicolumn{2}{c|}{ Categories } & 1 Button jacket & 2 Button jacket & 3 Button jacket & 4 Button jacket & Body size \\
\hline \multirow{4}{*}{$\begin{array}{c}\text { Researcher's } \\
\text { jacket }\end{array}$} & Chest ease & $105(\mathrm{C}+7.5)$ & $108(\mathrm{C}+10.5)$ & $108(\mathrm{C}+10.5)$ & $111(\mathrm{C}+13.5)$ & 97.5 \\
\cline { 2 - 8 } & Waist ease & $94.3(\mathrm{~W}+10.5)$ & $97.3(\mathrm{~W}+13.5)$ & $97.3(\mathrm{~W}+13.5)$ & $100.3(\mathrm{~W}+16.5)$ & 83.8 \\
\cline { 2 - 8 } & Hip ease & $104.3(\mathrm{H}+9)$ & $107.3(\mathrm{H}+12)$ & $107.3(\mathrm{H}+12)$ & $110.3(\mathrm{H}+15)$ & 95.3 \\
\hline \multirow{3}{*}{$\begin{array}{c}\text { Character } \\
\text { casual jacket }\end{array}$} & Chest ease & $104.2(\mathrm{C}+7.4)$ & $104.9(\mathrm{C}+8.1)$ & $105.8(\mathrm{C}+9)$ & $106.9(\mathrm{C}+10.1)$ & 96.8 \\
\cline { 2 - 8 } & Waist ease & $93.9(\mathrm{~W}+12.4)$ & $94.3(\mathrm{~W}+12.8)$ & $95.3(\mathrm{~W}+13.8)$ & $96.3(\mathrm{~W}+14.8)$ & 81.5 \\
\cline { 2 - 8 } & Hip ease & $106.0(\mathrm{H}+8.9)$ & $106.5(\mathrm{H}+9.4)$ & $107.3(\mathrm{H}+10.2)$ & $108.3(\mathrm{H}+11.2)$ & 97.1 \\
\hline \multirow{3}{*}{$\begin{array}{c}\text { Formal suit } \\
\text { jacket }\end{array}$} & Chest ease & $109.6(\mathrm{C}+11.9)$ & $110.0(\mathrm{C}+12.3)$ & $111.0(\mathrm{C}+13.3)$ & $111.5(\mathrm{C}+13.8)$ & 97.7 \\
\cline { 2 - 8 } & Waist ease & $99.2(\mathrm{~W}+14.6)$ & $99.5(\mathrm{~W}+14.9)$ & $100.3(\mathrm{~W}+15.7)$ & $100.6(\mathrm{~W}+16.0)$ & 84.6 \\
\cline { 2 - 8 } & Hip ease & $110.0(\mathrm{H}+10.0)$ & $110.2(\mathrm{H}+10.2)$ & $110.9(\mathrm{H}+10.9)$ & $111.3(\mathrm{H}+11.3)$ & 100.0 \\
\hline
\end{tabular}

* Each pattern size of character casual jacket and formal suit jacket was obtained through the survey of men's wear brand from the previous research. 
는 의복에 여유분이 많을수록 착용감과 활동성은 좋아지기 때문인 것으로 판단된다. 정립 시보다는 동작 시 유의한 차이가 큰 것으로 나타났다.

셋째, 외관평가와 동작평가 결과를 비교 분석하 여 본 연구에서 제안하는 적정 여유분은 다음과 같 다. 1 버튼 재킷은 가슴둘레 $\mathrm{C}+7.5 \mathrm{~cm}$, 허리둘레 $\mathrm{W}+$ $10.5 \mathrm{~cm}$, 엉덩이둘레 $\mathrm{H}+9 \mathrm{~cm}$ 이다. 2 버튼 재킷과 3 버 튼 재킷은 가슴둘레 $\mathrm{C}+10.5 \mathrm{~cm}$, 허리둘레 $\mathrm{W}+13.5 \mathrm{~cm}$, 엉덩이둘레 $\mathrm{H}+12 \mathrm{~cm}$ 이다. 4 버튼 재킷은 가슴둘레 $\mathrm{C}+13.5 \mathrm{~cm}$, 허리둘레 $\mathrm{W}+16.5 \mathrm{~cm}$, 엉덩이둘레 $\mathrm{H}+15 \mathrm{~cm}$ 이다.

이상과 같이, 30 대 남성 표준체형의 슬림 핏 재킷 의 버튼 수에 따른 적정 여유분을 규명한 연구를 통 하여, 남성복 재킷의 버튼 수가 달라지면 적정 여유 분 또한 달라짐을 알 수 있었다. 이러한 연구결과는 남성복 브랜드 존과 버튼 수에 따른 재킷 사이즈와 재킷의 스타일에 따른 패턴설계방법에 대한 실태조 사를 한 선행연구(Kim et al., 2012)의 결과를 지지 하는 것으로 시사하는 바가 크다고 할 수 있다.

후속연구로는 재킷의 둘레항목의 여유분 변화와 더불어 재킷의 버튼 수에 따라 브이-존의 영역이 달 라짐으로 인해 앞목너비와 뒷목너비도 변화하기 때 문에 재킷의 버튼 수에 따른 앞목너비와 뒷목너비 의 관계에 대한 연구를 제안한다.

\section{References}

Kim, J. S., \& Lee, W. J. (2004). A study on the design of men's jacket pattern. The Research Journal of the Costume Culture, 12(6), 953-970.

Kim, M. J., \& Jo, J. S. (2006). A study on the basic pattern of men's casual jacket. Journal of the Korean Society of Clothing and Textiles, 30(2), 207-220.

Kim, M. J., Kim, M. O., \& Park, S. K. (2014). Comparison and analysis of men's classic-fit and slim-fit shirt patterns: Utilizing the 3D virtual try-on system. The Research Journal of the Costume Culture, 22(2), 209-224. doi:10.7741/ rjcc.2014.22.2.209

Kim, M. O. (2015). Patternmaking of men's slim-fit jacket sloper in their 30's Part 2: Focusing on 6-panel jacket. Fashion \& Textile Research Journal, 17(1), 93-101. doi:10.5805/SFTI.2015. 17.1.93

Kim, M. O., \& Suh, M. A. (2011). Survey on purchase and fitting of menswear suits according to styles for consumers in their 30s. The Research Journal of the Costume Culture, 19(1), 191-199.

Kim, M. O., \& Suh, M. A. (2014). Patternmaking of men's slim-fit jacket sloper in their 30's Part 1: Focusing on four-panel jacket sloper. Fashion \& Textile Research Journal, 16(2), 275-284. doi:10. 5805/SFTI.2014.16.2.275

Kim, M. O., Kim, I., \& Suh, M. A. (2012). Comparisons: Sizes in men's slim-fit jackets according to brand zones and number of buttons, and jacket patternmaking methods according to jacket styles. The Research Journal of the Costume Culture, 20(2), 184-194. doi:10.7741/rjcc.2012.20.2.184

Korean Agency for Technology and Standards. (2005). 5th Report of Korean Body Measurements. Seoul: Author.

Petrova, A., \& Asdown, S. (2008). Three-dimensional body scan data analysis: Body size and shape dependence of ease values for pants's fit. Clothing \& Textiles Research Journal, 26(3), 227-252. doi:10.1177/0887302X07309479

Uh, M. K. (2007). The development of jeans pattern according to shrinkage rate of washing finishing. Unpublished doctoral dissertation, Hanyang University, Seoul, Korea. 